\title{
IMPACTOS DA TECNOLOGIA DA INFORMAÇÃO E COMUNICAÇÃO NA APRENDIZAGEM DOS ALUNOS EM ESCOLAS PÚBLICAS DE SÃO CAETANO DO SUL (SP)
}

\author{
A. P. Bitante ${ }^{1}$, A. C. de Faria ${ }^{2}$, M. A. Gaspar ${ }^{3}$, J. V. I. Pascual ${ }^{4}$, D. A. Donaire ${ }^{5}$ \\ 1,4 Universidade Municipal de São Caetano do Sul, ${ }^{2,3,5}$ Universidade Nove de Julho \\ alessandra.bitante@gmail.com
}

Submetido em 19/03/2015 - Aceito em 22/10/2016

DOI: 10.15628/holos.2016.2876

\section{RESUMO}

O objetivo deste estudo é verificar a percepção dos professores sobre o impacto do uso da tecnologia da informação e comunicação (TIC) na aprendizagem dos alunos do Ensino Fundamental. Esta é uma pesquisa qualitativa descritiva feita por meio de estudo de caso único em uma escola de Ensino Fundamental de São Caetano do Sul (SP), tendo sido aplicado questionário semi-estruturado junto a doze professores. Os principais resultados evidenciaram que as ferramentas de TIC introduzidas possibilitaram a consulta, pesquisa e produção de informações, viabilização de comunicação e intercâmbio dessas informações entre os participantes (gestão escolar, professores e alunos), além de permitir o desenvolvimento das disciplinas e projetos. Paradoxalmente, embora a utilização de ferramentas de TIC seja grande, a maior parte dos professores $(91,7 \%)$ pesquisados não possui formação especializada, o que causa, na opinião dos respondentes, a subutilização das ferramentas.

PALAVRAS-CHAVE: Comunicação. Educação. Gestão Pública. Tecnologia da Informação e Comunicação.

\section{IMPACTS OF INFORMATION AND COMMUNICATION TECHNOLOGY IN LEARNING OF STUDENTS IN PUBLIC SCHOOLS OF SÃO CAETANO DO SUL (SP)}

\begin{abstract}
The objective of this study is to verify the perception of teachers about the impact of the use of information technology and communication (ITC) in learning of elementary school students. This is a descriptive qualitative research by means of a single case study in a Primary School in São Caetano do Sul (SP) and applied semi-structured questionnaire with twelve teachers. The main results showed that the ITC tools made possible the consultation, exploration and production of information, enabling communication and exchange of such information among the participants (school management, teachers and students), and allows the development of disciplines and projects. Paradoxically, although the use of ITC tools is large, most of the teachers (91.7\%) surveyed do not have specialized training, which causes, in the opinion of respondents, the under-utilization of tools.
\end{abstract}

KEYWORDS: Communication. Education. Information Technology and Communication. Public Management. 


\section{INTRODUÇÃO}

Diante de grandes transformações envolvidas na utilização da Tecnologia da Informação e da Comunicação (TIC) nas esferas privada e pública, as pessoas necessitam pensar com cuidado o presente, apontando questões e procurando possíveis soluções de apreensões, interpretações e entendimentos, conforme expressa Zuin (2010). Enfim, o desenvolvimento de maior compreensão no sentido de construírem trajetórias progressistas diante das transformações.

Outra preocupação volta-se ao preparo dos profissionais da Educação para trabalharem e aplicarem a TIC em suas aulas, visando à melhoria do aprendizado de seus alunos. Face ao exposto, a simples alfabetização digital é considerada não suficiente e, muitas vezes, prioritária na formação do professor; notadamente quando é feita de forma isolada dos conceitos epistemológicos, filosóficos e sociológicos que subjazem às Ciências da Educação e às Políticas Públicas.

Estes são conceitos fundamentais para a elaboração de um projeto pedagógico pertinente, seja de formação inicial ou continuada. Assim, é a Educação que, não só fundamenta, como, também altera o significado do emprego das TICs em suas práticas (Zuin, 2010).

Sob esta perspectiva, os fundamentos epistemológicos, filosóficos e sociológicos, subjacentes às políticas públicas educacionais é que determinam a forma de utilização dos recursos da TIC junto aos currículos das formações inicial e continuada, e não o contrário (Pino, 2008).

Numa sociedade em que a tecnologia ocupa posição decisiva, aponto de alterar as configurações das relações humanas em todas as suas esferas, a discussão dos eixos direcionadores das futuras políticas públicas de Educação não pode abster-se de uma análise mais apurada sobre o modo como as atuais relações de produção determinam transformações cada vez mais aceleradas na esfera mais ampliada da estrutura nas instituições que a compõe, principalmente as escolares. Dessa maneira, as políticas públicas educacionais devem incorporar a discussão sobre o modo como tais recursos tecnológicos alteram as características das teorias e práticas pedagógicas (Zuin, 2010).

As mudanças das teorias, práticas e identidades estão no contexto da cultura da convergência, destacada por Jenkins (2008), na qual denota ser possível aumentar o controle das empresas de mídia sobre as TIC, quanto aos acessos e participações mais amplas e democráticas no uso de recursos das redes sociais ou comunidades, blogs e outros meios de comunicação. Nesse sentido, Burbules e Callister (2008) asseveram ser fundamental questionar como, quem e com que finalidades as novas tecnologias são utilizadas, sendo este mais um aspecto com que a gestão pública da Educação deve focalizar esforços.

No Brasil, conforme Barreto (2003), um objetivo de ordem geral explicitado no Plano Nacional de Educação - PNE (2001), em vigência desde a Lei n. 10.172/2001, é a redução das desigualdades sociais e regionais, principalmente no tocante ao acesso e à permanência, com sucesso, da criança e do adolescente na Educação Pública. 
Assim, a preocupação com a infraestrutura, com novos métodos e recursos pedagógicos que acompanhem as mudanças e estimulem os alunos a permanecerem nas escolas, deve ser uma preocupação principal. Embora tais vertentes envolvam financiamentos, perfazem-se como um instrumento das políticas públicas, cuja formulação envolve diversos fatores, dentre os quais a preocupação com a inclusão digital (Barreto, 2003).

A presente pesquisa busca responder à seguinte questão-problema: Qual a percepção dos professores sobre o impacto do uso da TIC na aprendizagem dos alunos do 10 ao 5o ano do Ensino Fundamental? Face ao exposto, o objetivo deste estudo é verificar a percepção dos professores sobre o impacto do uso da TIC na aprendizagem dos alunos do 1 o ao 5o ano do Ensino Fundamental.

\section{REVISÃO DA LITERATURA}

\subsection{Gestão Pública da Educação Brasileira}

O Governo tem papel fundamental no planejamento e implantação da gestão da Educação em um país. A União tem um papel primordial, pois é responsável pelo repasse de verbas. $\mathrm{O}$ apoio financeiro da União é realizado mediante a transferência de recursos provenientes do Fundo Nacional de Desenvolvimento da Educação para os fundos estaduais e municipais, repasse este executado pelos estados e municípios.

A Constituição Federal garante que a União deverá aplicar 18\% dos impostos em Educação e os Estados e Municípios 25\%. De acordo com o Instituto de Estudos Socioeconômico - INESC (2014), os Estados recebem recursos de acordo com o número de matrículas no ensino fundamental e médio, já os Municípios com base no Ensino Fundamental e Educação Infantil.

O Fundo de Manutenção e Desenvolvimento da Educação Básica e de Valorização dos Profissionais da Educação - FUNDEB - foi criado pela Emenda Constitucional no 53/2006 e regulamentado pela Lei $n$ ㅇ $11.494 / 2007$ e pelo Decreto $n=6.253 / 2007$, em substituição ao Fundo de Manutenção e Desenvolvimento do Ensino Fundamental e de Valorização do Magistério FUNDEF, que vigorou de 1998 a 2006.

Este é um fundo especial, de natureza contábil e de âmbito estadual (um fundo por estado e Distrito Federal), formado, na quase totalidade, por recursos provenientes dos impostos e transferências dos Estados, Distrito Federal e municípios, vinculados à educação por força do disposto no art. 212 da Constituição Federal. Independentemente da origem, todo o recurso gerado é redistribuído para aplicação exclusiva na Educação Básica, conforme o Fundo Nacional de Desenvolvimento da Educação - FNDE (2014).

Conforme Azevedo (2009), a Constituição de 1988 reconheceu e registrou os direitos sociais. Dessa forma, as demandas sociais por um novo padrão de políticas públicas devem ser atendidas pela melhoria da gestão pública. A Educação brasileira, desde meados da década de 1970, apresenta problemas relativos aos baixos níveis de escolarização da população. A gestão 
pública da educação foi definida em lei na Constituição vigente, por meio da Lei de Diretrizes e Bases da Educação Nacional - LDB.

A Constituição Federal de 1988 e a LDB de 1996 atribuiu à União, aos estados e municípios a responsabilidade pela administração do sistema educacional brasileiro que é mantido em regime de colaboração. Assim, os municípios atuam, principalmente, na Educação Infantil e Ensino Fundamental; o Estado assegura prioritariamente o Ensino Médio e o Ensino Fundamental e a União organiza o Ensino Superior e apoia técnica e financeiramente os entes federados. O papel do município é priorizar a Educação Infantil e o Ensino Fundamental, investindo as verbas oriundas dos impostos para a melhoria e ampliação deste ensino (Gouveia, \& Pelona, 2010).

A LDB regulamentou a gestão democrática da escola para garantir formas adequadas de participação dos vários educadores, proporcionando maior articulação entre escola e comunidade (Azevedo, 2009). Os profissionais da Educação devem ter assegurada a participação na elaboração do projeto pedagógico da escola.

A referida lei, também garante a participação das comunidades escolar e local em conselhos escolares ou equivalentes. Os sistemas de ensino devem assegurar para as suas unidades escolares públicas de educação básica, progressivos graus de autonomia pedagógica, administrativa e de gestão financeira, respeitando o cumprimento das normas gerais de direito financeiro público (Azevedo, 2009).

A melhoria da qualidade da Educação exige medidas que assegurem ao aluno seu ingresso e a permanência na escola. Para reverter a situação de baixa qualidade da aprendizagem na Educação Básica, faz-se necessário identificar os fatores relativos à política de gestão e refletir a construção de estratégias de mudança do quadro atual (Dourado, 2007).

De acordo com Azevedo (2009), em 2004, o Presidente Luís Ignácio Lula da Silva anunciou a implementação de mudanças nas políticas de Educação Pública para a democratização da gestão da Educação Básica no Brasil. As modificações foram: reformulação do Programa de Apoio aos Secretários Municipais de Educação - PRASEM convertido em Programa de Apoio aos Dirigentes Municipais de Educação - PRADIME; criação do Pró-Conselho, programa para fortalecer os Conselhos Municipais de Educação - CME, e do Programa Nacional de Fortalecimento dos Conselhos Escolares. Mesmo com essas mudanças, existem ainda vários problemas para particularizar as necessidades locais e oferecer reais ferramentas de auxílio à gestão e democratização da Educação.

Conforme Gouveia e Souza (2010), o Plano Nacional de Educação - PNE regulamenta a gestão da Educação e da escola, de maneira articulada ao seu financiamento. Na Conferência Nacional de Educação - CONAE são feitas análises sobre esses temas e o documento final deste evento em 2010 discute e consolida a concepção de gestão democrática, vinculada à ampliação do direito à educação, inclusão, qualidade social e avaliação emancipatória.

A principal dificuldade para a construção do Sistema Nacional Articulado de Educação está associada ao pacto federativo. O texto final da CONAE explicitava a preocupação dos diferentes segmentos representados com a necessidade de ampliação de recursos: 
- Ampliar o investimento em educação pública em relação ao PIB, na proporção de, no mínimo, 1\% ao ano, de forma a atingir, no mínimo, 7\% do PIB até 2011 e, no mínimo, 10\% do PIB até 2014, respeitando a vinculação de receitas à educação definidas e incluindo, de forma adequada, todos os tributos (CONAE, 2010, p. 110);

- Garantir o aumento dos recursos da educação de $18 \%$ para, no mínimo, $25 \%$ da União e de $25 \%$ para, no mínimo, 30\% (de estados, DF e municípios) não só da receita de impostos; mas adicionando-se, de forma adequada, percentuais das taxas e contribuições sociais para investimento em manutenção e desenvolvimento do ensino público (CONAE, 2010, p. 111).

Deve-se considerar o papel essencial das políticas de financiamento e regulação da educação, uma vez que os processos de gestão educacional e escolar são fortemente induzidos pela lógica decorrente do financiamento adotado; que, por sua vez, é resultante da caracterização do Estado e da articulação entre as esferas pública e privada (Dourado, 2007).

Vale ressaltar a busca de políticas, sobretudo no âmbito federal e de alguns governos estaduais e municipais, na década de 1990, quando, em consonância com a reforma do Estado e a busca de sua modernização, foram implementados novos modelos de gestão, cuja política objetivava, de acordo com Oliveira (2000), a introduzir na gestão pública noções de produtividade, eficiência e racionalidade, consideradas inerentes ao capitalismo.

Como exemplo, pode ser citado, o programa Dinheiro Direto na Escola consiste no repasse anual de recursos por meio do Fundo Nacional de Desenvolvimento Escolar - FNDE às escolas públicas do ensino fundamental estaduais, municipais e do Distrito Federal e às do ensino especial mantidas por organizações não governamentais (ONGs), desde que registradas no Conselho Nacional de Assistência Social - CNAS (Oliveira, 2000).

Os recursos, oriundos predominantemente do salário-educação, são destinados à aquisição de material permanente e de consumo necessários ao funcionamento da escola; à manutenção, conservação e pequenos reparos da unidade escolar; à capacitação e ao aperfeiçoamento de profissionais da educação; à avaliação de aprendizagem; à implementação de projeto pedagógico; e ao desenvolvimento de atividades educacionais.

O Programa foi criado pela Secretaria de Educação Básica do Ministério da Educação, mediante a Portaria Ministerial 2.896/2004 e visava à implantação e fortalecimento de conselhos escolares nas escolas públicas de Educação Básica nas cinco regiões do país, envolvendo os sistemas de ensino públicos estaduais e municipais, por meio de sua adesão à sistemática de apoio técnico, pedagógico e financeiro do Ministério da Educação (Dourado, 2007).

Conforme este autor, tais questões alinham-se às condições objetivas da população, pois o Brasil é um país historicamente demarcado por forte desigualdade social, revelada nos indicadores sociais preocupantes, o qual carece de amplas políticas públicas, como a garantia de otimização nas políticas de acesso, permanência e gestão, com qualidade social, na Educação Básica.

O investimento em Educação Básica, tendo a qualidade como foco principal de suas diretrizes, metas e ações e garantindo a essa qualidade uma dimensão sócio-histórica e, portanto, inclusiva, é um desafio para o país, em especial para as políticas e gestão desse nível de ensino. A 
qualidade social da Educação implica assegurar um processo pedagógico pautado pela eficiência, eficácia e efetividade social, de modo a contribuir com a melhoria da aprendizagem dos alunos em consonância à melhoria das condições de vida e de formação da população.

Dessa maneira, o papel da escola no Ensino Fundamental é auxiliar o aluno a reconhecer e vivenciar o prazer de aprender e buscar solução para as dúvidas; bem como, também a superar suas dificuldades. Pode-se fazer isso por meio da definição de estratégias de ação que se constituam em um convite para que sejam trazidos os conhecimentos anteriores que serão compartilhados, e que se constituirão na base para investigações futuras que devem acontecer de maneira ativa, participativa e criativa, ganhando significado numa forma adequada de registro que favoreça o compartilhar (Barbosa, 2004).

Os professores devem estimular e fazer a manutenção do interesse dos alunos pela escola, criando ações concretas que incentivem os alunos a buscar e a realizar. Cabe ao professor, por meio dos instrumentos a ele disponibilizados, criar tais ações/condições sempre pensando na melhor forma de estimular o aprendizado para seus alunos (Oliveira, 2005).

O papel da tecnologia, no Ensino Fundamental, foco deste trabalho, é o de oferecer suporte ao novo paradigma de ensino, apoiando a nova pedagogia a partir da qual os alunos ensinam a si mesmos com a orientação do professor. A tecnologia não corresponde à antiga pedagogia do professor que fala/palestra, exceto em formas mínimas, tais como a utilização de imagens ou vídeos (Prensky, 2010). Isso requer que haja inovação.

\subsection{Inovação na gestão pública}

De acordo com a Organização para Cooperação e Desenvolvimento Econômico - OCDE (2005), no Manual de Oslo são definidos os conceitos básicos sobre inovação. A inovação é caracterizada quando a invenção/nova criação gera uma aplicação prática de sucesso, e pode ser dividida em quatro tipos: inovação de produto, de processo, organizacional e de marketing.

Conforme Tidd, Bessant e Pavitt (2004), uma organização inovadora deve possuir uma estrutura organizacional inovadora, com processos inovadores, liderança inovadora, gestão inovadora de equipes de trabalho e participação ativa e inovadora dos empregados. Assim, a organização inovadora deve buscar continuadamente novas vantagens competitivas. Este autor segrega a inovação em incremental, pequenas inovações, inovação radical e inovação total, gerando um produto/serviço totalmente novo.

A inovação organizacional é o desenvolvimento de novos métodos organizacionais ou de gestão nas práticas de negócio da empresa ou de uma instituição, na organização do trabalho ou em suas relações externas. Inovações organizacionais visam à melhoria do desempenho de uma empresa ou instituição por meio da redução de custos administrativos ou de custos de transação, estimulando a satisfação no local de trabalho (e assim a produtividade do trabalho), ganhando acesso a ativos não transacionáveis (como o conhecimento externo não codificado) ou reduzindo os custos de suprimentos (Tidd, Bessant, \& Pavitt, 2004). 
As inovações organizacionais em práticas de negócio compreendem novos métodos para a organização de rotinas e procedimentos para a condução do trabalho. Isso inclui, por exemplo, o desenvolvimento de novas práticas para melhorar o compartilhamento do aprendizado e do conhecimento (Cavagnoli, 2009).

O avanço tecnológico ocorrido, principalmente, nos últimos dois séculos pós-Revolução Industrial, coincide ao que Schumpeter (1984) chama de 'destruição criativa', que caracteriza e define o capitalismo. A inovação provoca um processo de destruição criativa, no qual velhas estruturas são substituídas por novas, conduzindo a economia a níveis mais elevados de renda e presumivelmente de bem-estar social. Schumpeter (1984) afirma que as empresas capitalistas têm de atuar neste ambiente de inovação.

Numa visão mais macroscópica, também os governos estão inseridos neste ambiente. 0 autor afirma que os elementos inerentes à estratégia de negócios devem ser continuamente compreendidos a partir da visão da destruição criativa, não podendo ser interpretados sob um prisma de calmaria (Schumpeter, 1984). Neste caso, é possível alterar a estratégia de negócios, ao nível privado, por estratégia de Governo, ao nível público; que, também não poderia ser vista sob a hipótese da calmaria; pelo contrário, o período é justamente caracterizado por mudanças profundas, o que justifica a existência da destruição criativa, ou seja, o ambiente de inovação, também na esfera pública.

A inovação na gestão pública representa um amplo campo de possibilidades. De um lado, as inovações estruturais na área pública, que decorrem da implementação de uma nova concepção/prática de política pública. E de outro lado, a atuação da gestão pública, pois se torna relevante explicitar o que pode ser considerado inovador na gestão pública, tomando como referencial, exemplos, experiências e dinâmicas de institucionalização, dessa maneira ampliando seu alcance (Jacobi, \& Pinho, 2006).

\subsection{Promoção de Inovação na Educação Pública}

Kramer e Nunes (2007) afirmam que as Secretarias de Educação têm muita importância na formação continuada dos professores no Ensino Fundamental. Devem promover parcerias com universidades e faculdades para facilitar a formação continuada na busca da inovação e melhoria das práticas pedagógicas. Na gestão da Educação Pública é necessário conhecer as experiências dos alunos e professores, visando a construir a proposta pedagógica, organizar as rotinas, cuidar e educar.

O parecer de Mozart Neves Ramos entregue ao CNE, intitulado 'Arranjo de Desenvolvimento da Educação', preconiza o desenvolvimento de metodologia que apoie municípios e permita o desenvolvimento de ações e indicadores educacionais para buscar a melhoria da qualidade da Educação no âmbito local, dessa forma incentivando o regime de colaboração (Abicalil, 2013).

Carvalho (2009), por sua vez, aponta que, no sistema educacional brasileiro os indicadores de desempenho são obtidos pelo Sistema de Avaliação da Educação Básica - SAEB e pelo Índice de 
Desenvolvimento da Educação Básica - IDEB, que devem informar sobre a eficiência e produtividade dos serviços educacionais.

O modelo de gestão pública brasileiro no setor educacional deve utilizar novas formas e combinações de financiamento, fornecimento, regulação e controle. A escola deve ter mais autonomia, diminuindo a dependência do Estado e permitindo, assim uma gestão mais próxima aos moldes de uma empresa privada (Carvalho, 2009). Muitos municípios brasileiros implementaram parcerias para a execução de políticas educacionais. Dessa forma, buscaram atender às suas demandas, superando os problemas educacionais e, modernizando a gestão escolar (Peroni, Oliveira, \& Fernandes, 2009).

A inovação passa a ser preocupação da gestão pública, uma vez que esta começa a perceber a inovação diante do imperativo econômico da competitividade internacional e das complexidades sociais decorrentes do desenvolvimento tecnológico. Em um cenário de poucos investimentos e esvaziamento do papel do Governo, os Estados tiveram que criar condições de modernização e de democratização, por meio de formulação de políticas e diretrizes gerais, descentralização do sistema e a participação dos educadores e das comunidades interessadas. Dessa maneira, a inovação passa a ser valorizada como estratégia política no quadro das transformações do Estado. Atualmente, é o sistema que exige das escolas e seus profissionais, contínuo empenho inovador, sob total responsabilidade dos atores locais.

Para Chávez (1995), a escola tem parte de uma visão epistemológica como espaço único, específico, com sua própria identidade e atores distintos. É nesse espaço que a política educacional definida pelo Estado deve ser debatida, analisada, reconstruída, para que tenha uma concretização institucional.

As inovações são resultantes da construção da identidade da escola, mediante trabalho coletivo que vincule interesses e posições diferentes diante de objetivos comuns, ou seja, são projetos que fazem parte da proposta educacional da escola e que resultam de um processo de negociação entre os atores envolvidos (Mitrulis, 2002).

Deve-se considerar para a estrutura básica da Educação a definição do papel desta na sua relação coma sociedade, a concepção de ciência e conhecimento, as concepções de ensino e de aprendizagem e, ainda a ideia sobre as características psicológicas do ser que aprende, dentre outras. Drucker (2000) afirmou que as escolas sofrerão mudanças e inovações profundas, muito mais do que aconteceu até um passado recente. Atualmente, as novas TICs e a perspectiva da aprendizagem contínua têm criado novas demandas sociais, exigindo das organizações e dos governos respostas inovadoras. Conforme Drucker (2000):

\footnotetext{
A organização para a mudança requer um alto grau de descentralização. Isto porque a organização deve ser estruturada para tomar decisões rapidamente. E essas decisões devem ser baseadas na proximidade - com o desempenho, com o mercado, com a tecnologia, e com todas as muitas mudanças ocorrentes na sociedade no meio ambiente, na demografia e no conhecimento que propiciarão as oportunidades para a inovação (Drucker, 2000, p. 07).
} 
Senge (1996), por sua vez, destaca que uma atitude fundamental em qualquer inovação é o compromisso entre os que estão envolvidos no projeto de mudança. Isto porque inovação e mudança não podem ser separadas, mas só acontecem quando as pessoas envolvidas desejam aprender, mudar, adquirir novos conhecimentos, alterar conceitos e ideias trabalhadas, quebrar paradigmas para assumir novos comportamentos e atitudes, para repensar a cultura pessoal e organizacional vivida até aquele momento, para mudar suas próprias crenças e aderir a novas e fundamentais maneiras de pensar e de agir. Na área da Educação, Imbernón (2000) desenvolve reflexões interessantes sobre o futuro, muito próximas às ideias sobre inovação na Educação, destacando quatro ideias-força na base da mudança que devem impulsionar o futuro da Educação:

\begin{abstract}
A recuperação, por parte dos professores e demais agentes educativos, do controle sobre seu processo de trabalho; a valorização do conhecimento, tanto daquele já adquirido e desenvolvido pelas gerações e culturas anteriores, que tem seu valor e importância mesmo nos dias de hoje, mas que se apresenta como insuficiente para os próximos tempos, quanto dos novos conhecimentos que são investigados e produzidos atualmente em novas condições de número de informações, de velocidade de comunicação e de proliferação de fontes de conhecimento; a valorização da comunidade como verdadeira integrante do processo educativo, da comunidade de aprendizagem, co-responsável pelo projeto pedagógico da instituição; a diversidade como projeto cultural e educativo (Imbernóm, 2000, p. 80).
\end{abstract}

Barroso (2001) argumenta, de forma definitiva, que a gestão pública da Educação seja o motor para a busca da introdução da inovação na Educação, buscando e aplicando recursos, como reunindo os atores envolvidos e motivando-os para o alcance dos objetivos traçados. Conforme Zuin (2010), as inovações tecnológicas implicam na mudança de hábitos para a infância, juventude e velhice. Essas inovações implicam numa sociedade em rede dependente da tecnologia. $O$ uso da TIC, por exemplo, pode conduzir ao recrudescimento do poder e controle social ou ao reforço das práticas democráticas. O documento final do CONAE já considerava o uso da TIC na Educação, a partir de considerações que foram utilizadas para a criação das diretrizes e estratégias de ação do PNE (CONAE, 2010).

O PNE 2011-2010 apresenta critérios para uma política de formação e valorização dos profissionais da Educação. Nesse modelo de formação, são consideradas as inclusões necessárias para o uso adequado da TIC no processo de ensino-aprendizagem. O processo de alfabetização digital é relevante e deve ser implementado nos projetos pedagógicos. Essa alfabetização digital permite utilizar as tecnologias digitais para ministrar os conteúdos e possibilitar o aprendizado efetivo para o aluno (ZUIN, 2010).

Na visão de Selwyn (2008), a sociedade do início do Século XXI está extremamente globalizada e tecnológica, convivendo numa lógica social menos linear, estruturada e predizível. $\mathrm{Na}$ Educação, os indivíduos devem aprender vários conhecimentos e competências em diferentes modos, em função das exigências de sua situação e ser eternos alunos, independente da sua idade ou nível de Educação.

A aprendizagem poderá ocorrer em instituições de ensino formais ou com aprendizado à distância. Para tanto, o papel do computador e da TIC é evidenciado por Rodrigues e Colesanti (2008), aos discorrerem que estes devam ser utilizados como uma ferramenta cognitiva, que não 
busque somente a informação; mas, também estimule os usuários a acessar, analisar, interpretar e organizar seu conhecimento pessoal com o uso de problemas propostos.

Cysneiros (2000) considera que a tecnologia educacional deve envolver algum tipo de objeto material, que faça parte de alguma ação educativa; portanto relativa a processos de ensino e de aprendizagem, havendo algum tipo de relação entre o educador e a tecnologia. Estes julgamentos relacionam-se com a percepção que o sujeito tem sobre o computador; os quais, por sua vez, relacionam-se, com as experiências, conhecimentos, habilidades e interesses, e podem favorecer a ampliação de alguns aspectos em detrimento a outros.

Selwyn (2008) afirma que existem duas formas principais do uso de tecnologias para melhoria dos resultados educacionais e promoção da inclusão social na Educação: uso de tecnologias para promover a inclusão social em termos de oportunidades e resultados educacionais e o uso da Educação para garantir a inclusão social em termos de oportunidades e resultados tecnológicos.

Rodrigues e Barbieri (2008) consideram que a tecnologia apropriada deve se ajustar a algum propósito ou uso específico; e este conceito evoluiu para o conceito de tecnologia social. Para o Instituto de Tecnologia Social, a tecnologia social pode ser classificada como "um conjunto de técnicas de metodologias transformadoras, desenvolvidas e/ou aplicadas na interação com a população e apropriadas por ela, que representam soluções para a inclusão social e melhoria das condições de vida" (ITS, 2004, p. 26).

Bazzo (1998) destaca que é inegável a contribuição que a Ciência e a Tecnologia trouxeram; porém, não se pode confiar excessivamente nelas e deixar-se levar pela comodidade que é proporcionada por estes dispositivos, pois se pode esquecer que a Ciência e a Tecnologia incorporam questões sociais, éticas e políticas. As pessoas precisam ter acesso a elas, não somente conhecendo, mas utilizando como produtos ou conhecimentos e devem opinar sobre o uso. De acordo com Medina e Sanmartín (1990), quando o foco é incluir a TIC no contexto educacional, faz-se importante que alguns objetivos sejam atendidos:

- Questionar as formas herdadas de estudar e atuar sobre a natureza, as quais devem ser constantemente refletidas. Sua legitimação deve ser feita por meio do sistema educativo, pois só assim é possível contextualizar, permanentemente, os conhecimentos em função das necessidades da sociedade;

- Questionar a distinção convencional entre conhecimento teórico e conhecimento prático - assim como sua distribuição social entre "os que pensam" e "os que executam" - que reflete, por sua vez, um sistema educativo dúbio, que diferencia a educação geral da vocacional;

- Combater a segmentação do conhecimento, em todos os níveis de Educação;

- Promover uma autêntica democratização do conhecimento científico e tecnológico, de modo que esta não só se difunda, mas que se integre na atividade produtiva das comunidades de maneira crítica.

A importância de discutir com os alunos os avanços da Ciência e Tecnologia, suas causas, consequências, os interesses econômicos e políticos, de forma contextualizada, está no fato de que se deve conceber a Ciência como um resultado da criação humana. A ideia de inserir na sala 
de aula o debate sobre as relações existentes entre Ciência, Tecnologia e Sociedade - tanto no Ensino Fundamental quanto no Ensino Médio, vem sendo difundida por meio dos Parâmetros Curriculares Nacionais (PCNs), como forma de Educação Tecnológica para a compreensão da origem e do uso que se faz desses dispositivos e tecnologia (Pinheiro, Silveira, \& Bazzo, 2007).

Entre outros autores que vêm escrevendo sobre TIC's e ressaltando sua importância para a Educação, podem ser citados: na Espanha, estão Palácios et al. (1996); Sanz, Mortálla e Goméz (1996); Tortajada e Peláez (1997); Acevedo (2001); Cerezo (2002) e Acevedo, Alonso e Massanero (2004). No Brasil, os estudos sobre TIC aplicada à Educação podem ser encontrados em periódicos da área de Ensino de Ciências e Matemática, tais como, por exemplo: Revista Ensaio - Pesquisa em Educação em Ciências e Revista Ciência \& Educação, entre outras.

Alguns são também encontrados em livros, teses e dissertações e, entre outros, destacamse: Bazzo (1998); Mortimer e Santos (2000); Mion et al. (2001); Leal e Gouvêa (2001); Cruz (2001); Bazzo e Colombo (2001); Auler, (2002); Koepsel (2003) e Pinheiro (2005), entre outros.

Conforme Pinheiro, Silveira e Bazzo (2007), o professor é o grande articulador para garantir a mobilização dos saberes, o desenvolvimento do processo e a realização de projetos, nos quais os alunos estabelecem vínculos entre o conhecimento adquirido e o pretendido com a finalidade de resolver problemas, em consonância com suas condições intelectuais, emocionais e contextuais.

Enfatiza-se que o enfoque em TIC que venha a ser inserido nos currículos é, somente um início para o aluno, uma vez que o objetivo maior deve ser que o aluno assuma uma postura questionadora e crítica em sua vida. A tecnologia não pode ser utilizada somente na escola, mas em todos os ambientes em que possibilite aprendizado. Há a necessidade de buscar elementos para a resolução de problemas que fazem parte do cotidiano do aluno, ampliando-se esse conhecimento para utilizá-lo nas soluções dos problemas coletivos de sua comunidade e sociedade. Na sequência, serão descritos os aspectos metodológicos da pesquisa.

\section{METODOLOGIA DA PESQUISA}

Esta é uma pesquisa qualitativa descritiva. Conforme Gil (2002), algumas pesquisas descritivas vão muito além da identificação da existência de relações entre variáveis, que determinam a natureza dessa relação. Pesquisas dessa natureza aproximam-se de uma pesquisa explicativa. Neste tipo de pesquisa, normalmente os pesquisadores sociais estão preocupados com a atuação prática, sendo as mais solicitadas por organizações como instituições de ensino, o foco dessa pesquisa.

Já em relação à sua natureza qualitativa, tal análise tem muitas variáveis, tais como a natureza dos dados coletados, a extensão da amostra, os instrumentos de pesquisa e os pressupostos teóricos em que se baseia a investigação. Em pesquisas qualitativas, o conjunto inicial de categorias, em geral, é estudado e modificado várias vezes, para se chegar a resultados mais abrangentes e significativos (Gil, 2002; Moran, 2010).

Este é um estudo de caso único que buscou analisar o ponto de vista dos indivíduos sobre a importância do uso da TIC em uma escola de ensino fundamental selecionada por critérios de 
acessibilidade dos pesquisadores, localizada no município de São Caetano do Sul (SP). Não obstante, a escolha do município de São Caetano do Sul também se deveu ao fato de que esta localidade tem alcançado destaque no contexto da educação pública brasileira, como por exemplo, o primeiro lugar no IDH (índice de desenvolvimento humano) brasileiro, conforme dos do Programa das Nações Unidas para o Desenvolvimento - PNUD (2010).

Nesta pesquisa foi realizada a análise da percepção dos professores sobre o impacto do uso da TIC na aprendizagem dos alunos do 1으 ao 5o ano do Ensino Fundamental. Para a coleta de dados foi usado um questionário semi-estruturado, cujo objetivo foi a obtenção de dados, a partir do ponto de vista de doze respondentes, professores da escola em foco e que utilizam recursos de TIC em suas atividades de ensino-aprendizagem.

O questionário aplicado aos professores teve três perguntas abertas referentes à idade, ao motivo para uso ou não uso da tecnologia; três perguntas com múltiplas opções; uma pergunta com escala do tipo Likert de cinco pontos para a classificação dos conhecimentos como usuário de tecnologia, sendo: 1 - Nenhum conhecimento e 5 - Domínio Perfeito; duas perguntas com escala do tipo Likert para a classificação da frequência do uso de tecnologia na preparação e nas aulas, sendo 1 - Nunca usa e 5 - Empregou-se duas perguntas para assinalar em que contexto e atividades se utilizam os equipamentos de tecnologia.

Por fim, 33 perguntas com foco em conhecimento, formação, uso em aula e uso de equipamentos de TIC, utilizando-se uma escala do tipo Likert, 1 - Discordo Totalmente, 2 Discordo em parte, 3 - Não concordo e nem discordo, 4 - Concordo em parte e5 - Concordo Totalmente, em que os pesquisados deveriam apenas assinalar, de acordo com as afirmações propostas, a opção que mais se aproximava da sua realidade.

Foram, também realizadas entrevistas com a direção e os coordenadores da escola. O foco das entrevistas foi verificar a intenção da instituição em continuar a desenvolver projetos voltados à TIC. A análise de conteúdo das respostas obtidas foi realizada, de acordo com Bardin (1977), comparando-se as evidências encontradas ao longo das entrevistas com os padrões teóricos verificados na revisão da literatura, particularmente sobre a influência do uso da tecnologia na aprendizagem e a importância da gestão pública nesse aspecto.

Em complemento, a observação direta efetuada no ambiente prospectado auxiliou o processo de pesquisa. Dessa maneira, os pesquisadores ficaram inseridos no ambiente de aula, em que estão todos os recursos tecnológicos, tendo sido observado como estes eram utilizados e em que contextos, bem como a reação, a atitude e a participação dos alunos no uso desses recursos.

\section{RESULTADOS E DISCUSSÕES}

O estudo de caso foi desenvolvido em uma Escola Municipal de Ensino Fundamental EMEF, localizada no município de São Caetano do Sul (SP) que atende 346 alunos de 6 a 12 anos, correspondentes ao 10 ao 70 ano do Ensino Fundamental. Os alunos estão divididos em doze salas de aula, uma sala de robótica e um laboratório de informática. Conta com 30 professores, sendo 
que dezoito ministram aulas de oficinas de artes, música e robótica, uma vez que se trata de uma escola de período integral.

A escola possui 142 computadores, sendo que 23 pertencem à municipalidade e 119 às empresas parceiras, que serão tratadas posteriormente. Conta com outros equipamentos de tecnologia, tais como seis impressoras de jato de tinta, duas impressoras a laser, duas máquinas fotográficas digitais, quatorze data-shows e treze lousas-digitais instaladas nas salas de aula, dois scanners de mesa para projeção de textos impressos, duas impressoras multifuncionais, 88 netbooks para serem utilizados em sala de aula, 29 notebooks para utilização dos professores (já computados nos 142 computadores citados). Todos os computadores possuem conexão com a Internet, ou seja, tanto a área administrativa quanto professores e alunos têm acesso à Internet.

Todos os computadores do laboratório de informática e da administração possuem o pacote Office da Microsoft instalado, nas máquinas dos laboratórios, em que há seis jogos educativos instalados e os alunos possuem acesso ao Portal Aprender São Caetano (2014) com jogos e programas de conteúdo pedagógico contemplados no Projeto Educativo da escola. Para a manutenção dos equipamentos, há um departamento específico da Prefeitura. Quanto aos equipamentos dos parceiros, os próprios fazem manutenção, mediante abertura de chamados por parte dos usuários.

De acordo com a Direção e a Coordenação a escola, a Prefeitura tem intenção de continuar a desenvolver projetos na área de TIC. Os respondentes apontaram que essas parcerias com empresas prestadoras de serviços de tecnologia colaboram para o desenvolvimento escolar dos alunos; argumentando que, no mundo globalizado, torna-se essencial iniciar e desenvolver as competências tecnológicas dos alunos.

\subsection{Análise da implantação da TIC no Ensino Fundamental}

Para um entendimento mais fácil quanto às mudanças que ocorreram com a implantação das TICs no Ensino Fundamental da escola pesquisada, segue comparação da situação anterior e posterior à implantação:

\begin{tabular}{|l|l|l|}
\hline \multicolumn{1}{|c|}{ ATIVIDADE } & \multicolumn{1}{|c|}{ ANTES } & \multicolumn{1}{c|}{ DEPOIS } \\
\hline $\begin{array}{l}\text { Consulta e pesquisa de } \\
\text { informações }\end{array}$ & $\begin{array}{l}\text { Somente na Biblioteca em livros, } \\
\text { revistas, ou seja, impressos. }\end{array}$ & $\begin{array}{l}\text { Utilização de vídeos, computador } \\
\text { e internet para consulta. }\end{array}$ \\
\hline $\begin{array}{l}\text { Produção e edição de } \\
\text { informação }\end{array}$ & Reprodução, recortes desenhos. & $\begin{array}{l}\text { Utilização de câmera de vídeo e } \\
\text { edição com uso do computador. }\end{array}$ \\
\hline Comunicação e intercâmbio & $\begin{array}{l}\text { Por meio de ofícios e memorandos, } \\
\text { ou de maneira oral (informal). }\end{array}$ & $\begin{array}{l}\text { Por meio de e-mails e } \\
\text { compartilhamento } \\
\text { informações, utilizando o portal } \\
\text { disponibilizado pela prefeitura. }\end{array}$ \\
\hline Recreação & $\begin{array}{l}\text { No pátio da escola por meio de } \\
\text { brincadeiras lúdicas ou } \\
\text { tradicionais. }\end{array}$ & $\begin{array}{l}\text { Utilização da Internet para jogos } \\
\text { e vídeo. }\end{array}$ \\
\hline $\begin{array}{l}\text { Desenvolvimento } \\
\text { disciplina }\end{array}$ & $\begin{array}{l}\text { Feito com o apoio de livros, } \\
\text { revistas e impressos. }\end{array}$ & $\begin{array}{l}\text { Pesquisas pela internet e o uso de } \\
\text { vídeos e aulas virtuais. }\end{array}$ \\
\hline Projetos & $\begin{array}{l}\text { Utilização de recursos como } \\
\text { cartolina, canetinhas, massinhas } \\
\text { etc. }\end{array}$ & $\begin{array}{l}\text { Utilização de vídeos, recursos de } \\
\text { softwares disponibilizados no } \\
\text { computador e pesquisas na }\end{array}$ \\
\hline
\end{tabular}




\begin{tabular}{|l|l|l|}
\hline & & internet. \\
\hline Apoio pedagógico & Reuniões semanais presenciais. & $\begin{array}{l}\text { Reuniões semanais presenciais. } \\
\text { Cursos em EAD para formação. }\end{array}$ \\
\hline
\end{tabular}

\section{Quadro 1: $O$ antes e depois da implantação das TICs no Ensino Fundamental}

Fonte: Dados da pesquisa

Por meio do questionário aplicado, os professores apontaram que utilizam o vídeo para aulas expositivas, complementando o assunto abordado em sala, como por exemplo, um documentário sobre a história de cordéis. Já a câmera é utilizada para filmagem das atividades dos alunos e, posteriormente, exibição nas feiras que a escola realiza, como leitura de cordéis pelos alunos.

O computador é utilizado para o desenvolvimento de textos e desenhos, além de toda a pesquisa, com a utilização da internet. E essa utilização, também se estende à divulgação dos trabalhos desenvolvidos pelos alunos. Sem a tecnologia todas essas ações eram feitas, de maneira manual e com uma qualidade menor, conforme explicado pelos professores. Como resultado, foi possível verificar a importância da introdução da TIC para auxílio das aulas, o que resulta em uma melhoria do aprendizado.

\subsection{Frequência da utilização das TIC para a preparação e aplicação das aulas}

Constatou-se que $75 \%$ dos professores utilizam o recurso de vídeo apenas algumas vezes por mês. O data-show é utilizado, frequentemente, pela metade dos professores. O computador no laboratório de informática é utilizado várias vezes por semana, por metade dos professores, sendo que todos a utilizam basicamente para acessar a internet. A lousa digital disponível nas salas de aula é utilizada por $75 \%$ dos professores durante as suas aulas. 0 uso do netbook foi apontado por $25 \%$ dos professores que o utilizam apenas algumas vezes por mês. Já o notebook, é utilizado por $80 \%$ dos professores, várias vezes por semana.

Nas séries iniciais do Ensino Fundamental, o aluno encontra-se na fase das operações concretas, momento no qual o uso de recursos tecnológicos visa uma aprendizagem significativa, por meio da construção do conhecimento, com grande importância. Usando esses recursos, a apresentação dos conteúdos curriculares pode despertar o desenvolvimento de habilidades, aptidões, enfim, de capacidade cognitiva, possibilitando a assimilação do conhecimento historicamente elaborado de maneira prazerosa, já que combinam texto, som, imagem, animação e vídeo para manter a atenção e o interesse do aluno (Santos, \& Barros, 2008).

\subsection{Conhecimentos dos professores e sua formação para uso das TICs}

Os professores que não possuem formação especializada em Tecnologia da Informação correspondem a 91,7\%. Embora a maioria não tenha essa formação, os professores pesquisados apontaram que têm conhecimento suficiente no uso do vídeo correspondendo a $66,7 \%$. Já na utilização da lousa digital, 58,3\% apontaram que têm pouco conhecimento. 
No caso dos computadores, metade tem conhecimento suficiente, bem como no uso do scanner. Quanto ao uso do netbook, a porcentagem é de $41,7 \%$, que é a mesma no uso do notebook. Metade dos professores afirma que tem conhecimento suficiente para utilização da impressora e da internet.

Quando se aborda conhecimento em softwares educativos, 58,3\% têm pouco conhecimento, a mesma porcentagem corresponde ao conhecimento suficiente quando se trata do software MS Word, no caso do MS Excel. 41,7\% afirmam ter conhecimento suficiente, enquanto metade diz ter pouco conhecimento em MS PowerPoint. Metade afirma que esses conhecimentos foram adquiridos durante a sua formação acadêmica, enquanto a outra metade diz tê-los obtidos sozinhos (autodidata).

Abordando a formação, todos os professores concordam que se deveria implementar um programa de formação em tecnologias a todos os professores dos diferentes graus de ensino; sendo que $90 \%$ acreditam ser fundamental que futuros professores aprendam a trabalhar com as tecnologias.

A mesma porcentagem denota que deveria ser um objetivo das licenciaturas de formação de professores terem conhecimento sobre diferentes aplicações das TICs na sala de aula. 83\% discordam que a formação em tecnologias só poderá interessar a professores de certas disciplinas, nomeadamente Matemática ou Ciências. 75\% acreditam que se deva investir na formação, quer inicial quer contínua, se há a necessidade de que os professores utilizem as tecnologias na prática docente.

$80 \%$ dos professores pesquisados afirmam que a resistência de muitos professores para utilização das TICs na sala de aula deve-se, sobretudo, à falta de formação adequada. Esta mesma porcentagem de professores acredita que a razão principal para que os professores não utilizem as tecnologias na aula, está mais na falta de formação ou hábito do que na falta de equipamento disponível.

A grande maioria dos professores $(91,7 \%)$ concorda que não será possível atingir os objetivos das novas orientações curriculares sem capacitar os professores na área das tecnologias. Considera que as tecnologias são ferramentas pedagógicas indispensáveis à atividade docente devem constar de todos os planos de formação de professores, sendo que $80 \%$ consideram prioritário investir na formação de professores na área das tecnologias.

As instituições educacionais, tais como as escolas, as faculdades, as bibliotecas e os museus propiciam acesso às TICs, uma vez que se considera que a formação em competências e perícias tecnológicas fornece aos indivíduos as capacidades informacionais necessárias para tirar o melhor proveito das TICS. Assim, a formação continuada do pessoal docente em termos de uso das tecnologias no seu ensino se faz essencial (Selwyn, 2008). Para isto, é fundamental equipar as escolas e capacitar os professores para utilizá-las, especialmente nos cursos de Pedagogia e nas Licenciaturas, e integrar a informática na formação regular dos alunos (PNE, 2014). 


\subsection{Uso de TICs nas aulas}

A pesquisa teve como resultado que $70 \%$ dos professores conseguem ministrar suas aulas sem o uso das TICs; mas $90 \%$ afirmam que as TICs facilitam e melhoram as suas aulas; como, também facilitam o aprendizado dos alunos, sendo que o uso das TICs torna a aula mais atraente para os alunos.

Dos professores respondentes, $58,3 \%$ não se sentem pressionados ao trabalhar com as TICs; sendo que $66,7 \%$ se sentem confortáveis em falar sobre a aplicação das TICs em seus cotidianos. Já metade dos professores é indiferente quanto à sua participação em cursos sobre TICs voltadas às suas atividades. $66,7 \%$ dos professores apontaram que gostam de trabalhar com TICs, sendo que $80 \%$ afirmam que trabalhar com tecnologias é divertido e estimulante, e que é agradável frequentar cursos sobre estas tecnologias. Porcentagem idêntica que afirma se sentir bem trabalhando com tecnologias e que gostaria de aprender mais, pois se sente à vontade em aulas de tecnologias.

A diversidade de recursos de TIC existente na escola vai ao encontro das necessidades de professores e alunos, conforme apontado por $60 \%$ dos professores pesquisados. Já as condições ambientais das salas equipadas com TIC não favorecem a sua utilização, como citaram $60 \%$ dos professores, porcentagem idêntica aos que afirmam que a escola não se esforça por atualizar os recursos de TIC; embora a concentração das TICs em determinado setor da escola favoreça a sua utilização por professores e alunos, como apontam $70 \%$ dos professores.

O pessoal, os recursos físicos e materiais relativos às TICs são devidamente gerenciados, embora a formação profissional do pessoal auxiliar não corresponda às exigências das TICs, como apontado pelos professores. Metade dos professores concorda que os responsáveis pelos projetos e pelo órgão pedagógico têm papel encorajador junto dos colegas para usarem as TICs como recurso educativo.

A escola cria condições para que os alunos adquiram, cada vez mais, capacidades no domínio das TICs, conforme apontado por $75 \%$ dos professores e metade deles concorda que todos os alunos têm as mesmas oportunidades de acesso às TICs na escola, sendo que $80 \%$ afirmam que os recursos de TIC são divulgados junto à comunidade escolar.

Ter equipamentos é a condição básica para a realização de atividades pedagógicas diferenciadas. Os alunos atualmente têm bom conhecimento sobre o uso da tecnologia, principalmente, com os computadores, além do acesso à internet. Essa é uma característica que deve ser aproveitada pelo professor para trabalhar os conteúdos de currículos. Nesse contexto, a inclusão do computador no projeto pedagógico faz diferença no aprendizado desses alunos (Pinheiro, 2009).

Os professores percebem o potencial dessas ferramentas e procuram fazer atividades práticas com o uso das TICs. O fato é que o uso dessas tecnologias aproxima alunos e professores, além de ser útil na exploração dos conteúdos de forma mais interativa. $O$ aluno passa de mero receptor, que só observa e nem sempre compreende, para um sujeito mais ativo e participativo. A tecnologia, também auxilia o professor na busca por conteúdos a serem trabalhados (Ciranda, 2013). 


\section{CONCLUSÕES}

A gestão pública da educação possui importância crescente para melhorar a qualidade de vida dos cidadãos, proporcionando qualificação da mão-de-obra e potencial melhoria na renda familiar da população. Além disso, possibilita a melhoria dos indicadores econômicos dos governos.

Assim, essa faceta da gestão pública deve gerir a Educação, de forma ampla e integrada, considerando diferentes faixas etárias, desde a Educação Infantil (creche), Ensino Fundamental, Ensino Médio e Ensino Superior. Uma das preocupações dos gestores públicos quando atuam em Educação, volta-se ao acompanhamento das mudanças que ocorrem no mercado educacional, buscando a adaptação das escolas, bem como a introdução de novas formas e ferramentas que auxiliem no processo pedagógico.

Uma dessas preocupações é sobre como utilizar a TIC como uma ferramenta que auxilie o aprendizado e contribua para a formação dos alunos. A TIC tem atualmente espaço considerável e grande importância na sociedade contemporânea, e está inserida no dia-a-dia das pessoas em suas várias atividades. O investimento em TIC nas escolas é algo primordial para que o ensino acompanhe o estágio de desenvolvimento do mercado profissional.

No contexto brasileiro, a União repassa verbas para os Estados e municípios para que estes possam investir na melhoria da qualidade de Educação de suas escolas, sendo que uma das aplicações dessas verbas deve voltar-se a implantação e uso de ferramentas de TIC. Outra preocupação deve ser com a formação, atualização e especialização dos professores, para que estes utilizem essa tecnologia disponibilizada, da melhor maneira possível, e consigam melhorar suas aulas; alcançando a atração e permanência dos alunos na escola, considerando que a grande maioria desses alunos já manipula tais tecnologias.

Embora possa haver algumas dificuldades, pode-se verificar que os professores respondentes da pesquisa consideram de grande importância o uso da TIC em suas aulas e que estas auxiliam, tanto os professores quanto os alunos, quando o objetivo é o aprendizado. Nesse contexto, a adequada combinação de investimento, formação, uso e motivação, trazem benefícios para a formação dos alunos, facilitando o aprendizado e tornando as aulas mais agradáveis.

No atual contexto da sociedade, não há como se dissociar aprendizado e tecnologia, pois esta, quando bem utilizada, vem facilitar o aprendizado. Portanto, as escolas devem estimular o uso da tecnologia no processo de aprendizagem, aperfeiçoando seus professores e os incentivando a utilizar as ferramentas disponíveis. De outra parte, os municípios devem investir nessas tecnologias se desejam que a formação e aprendizagem de seus alunos correspondam às necessidades desse novo mundo digital.

No caso analisado neste estudo, pode-se verificar a introdução de diferentes TICs na escola pesquisada, visando a proporcionar a consulta, pesquisa e produção de informações, além de viabilizar comunicação e intercâmbio dessas informações entre os participantes (gestão escolar, professores e alunos). Por meio das TICs introduzidas foi, também possível melhorar o desenvolvimento das disciplinas e projetos, além da melhor prestação de apoio pedagógico aos 
professores. Já quanto aos recursos e ferramentas de TIC, os professores fazem maior uso de data shows, computadores, lousas digitais e notebook. Foi verificada menor frequência de uso de netbooks por parte dos professores.

Embora a utilização de ferramentas de TIC seja grande, a pesquisa demonstrou que a maior parte dos professores $(91,7 \%)$ pesquisada, não possui formação especializada em Tecnologia da Informação. Tal contexto verificado contribui para a subutilização das ferramentas de TIC, uma vez que os professores, por falta de capacitação, não conseguem usufruir de toda a potencialidade das ferramentas empregadas no processo de ensino-aprendizagem. O resultado quanto à baixa capacitação dos docentes no uso de TICs se mostra paradoxal, quando comparado com a percepção da maioria destes (90\%) de que as TICs facilitam e melhoram suas aulas, bem como o aprendizado dos alunos.

A pesquisa apresenta algumas limitações, como a prospecção de um estudo de caso único um uma determinada região geográfica, bem como a diminuta quantidade de professores analisados. Sugere-se que novas pesquisas e estudos sejam desenvolvidos sobre a importância da inovação em Educação Pública com foco em TIC, pois este uso nas escolas é algo relativamente recente.

Este estudo contribui para um melhor entendimento do impacto e potencialidades das ferramentas de TIC no processo de ensino-aprendizagem, notadamente sob o prisma da gestão da educação pública no país. Não obstante, também agrega conhecimentos acerca da figura do professor no processo de implementação de ferramentas TIC em escolas públicas, a partir do estudo de um município com destacada atuação na educação pública no país, como é o caso de São Caetano do Sul (SP).

Conclui-se por meio desta pesquisa que deve haver acompanhamento e verificação do quanto a tecnologia contribui no aprendizado; considerando, não somente no Ensino Fundamental, foco deste artigo, mas, em todos os níveis, inclusive na formação superior; para que se possa verificar se o aprendizado aliado à tecnologia contribui para a vida dos alunos, ou seja, para sua formação para um mercado de trabalho e sua vida em geral.

\section{REFERÊNCIAS}

Abicalil, C. A. (2013). Sistema nacional de educação: os arranjos na cooperação, parceria e cobiça sobre o fundo público na educação básica. Educação Social, 34 (124), 803-828.

Acevedo, J. A. D. A. (2001). La formación Del profesorado de enseñanza secundarias para La educación CTS: una cuestión problemática, $2001 . \quad$ Recuperado de: <http://www.campusoei.org/salactsi/acevedo9.htm>. Acesso em: 20 jun. 2014.

Acevedo, J. A. D. A., Alonso, Á. V., \& Massanero, M. A. (2004). Progresos em La evaluación de actitudes relacionadas com La ciencia mediante El cuestionario de opiniones, 2004. Recuperado de: <http://www.campus-oei.org/salactsi/acevedo.htm>. Acesso em: 20 jun. 2014.

Auler, D. (2002). Interações entre ciência-tecnologia-sociedade no contexto da formação de professores de ciências. Florianópolis: UFSC. 
Azevedo, J. M. L. (2009). Programas federais para a gestão da educação básica: continuidade e mudanças. RBPAE, 25 (2), 211-231, Maio/Ago.

Barbosa, M. S. S. (2004). O papel da escola: obstáculos e desafios para uma educação transformadora. Dissertação (Mestrado em Educação). Universidade Federal do Rio Grande do Sul. Porto Alegre.

Bardin, L. (1977). Análise de conteúdo. Lisboa: Edições.

Barreto, A. M. R. F. (2003). A educação infantil no contexto das políticas públicas. Revista Brasileira de Educação, 24, 53-65.

Barroso, J. (2001). Das reformas globais às mudanças locais. Anais... In: XX Simpósio Brasileiro de Política e Administração da Educação, Salvador.

Bazzo, W. A. (1998). Ciência, tecnologia e sociedade: e o contexto da educação tecnológica. Florianópolis: UFSC.

Bazzo, W. A., \& Colombo, C. R. (2001). Educação tecnológica contextualizada: ferramenta essencial para o desenvolvimento social brasileiro. Revista de Ensino de Engenharia, 20 (1), 9-16.

Brasil. (2015). Plano Nacional de Educação - PNE. Ministério da Educação. Brasília: Inep, 2015. Recuperado

<http://portal.mec.gov.br/index.php?option=com_content\&id=16478\&Itemid=1107>. Acesso em: 21 jun. 2015.

Burbules, N.C, \& Callister, T.A. (2008). Educación: riesgos y promesas de lãs nuevas tecnologías de La información. Buenos Aires: Granica.

Carvalho, E. J. G. (2009). Reestruturação produtiva, reforma administrativa do estado e gestão da educação. Educação Social, 30 (109), 1139-1166, Set./Dez.

Cavagnoli, I. (2009). Inovação organizacional. Gestão e Inovação. Recuperado de: <http://gestaoeinovacao.com/inovacao-organizacional/>. Acesso em: 19 jun. 2014.

Chávez, P. (1995). Seminario Taller Internacional de innovaciones educativas. Revista Latino americana de Innovaciones Educativas, 7 (20), 11-71.

Ciranda - Central de Notícias dos Direitos da Infância e Adolescência. 2013. Novas tecnologias já podem ser usadas em sala de aula. Disponível em: http://ciranda.org.br/novas-tecnologias-japodem-ser-usadas-nas-salas-de-aula/ Acesso em: 13 nov. 2014.

Cerezo, J. A. L. (2002). Ciência, tecnologia e sociedade: o estado da arte na Europa e nos Estados Unidos. In: SANTOS, L. W. (Org.). Ciência, tecnologia e sociedade: o desafio da interação. Londrina: IAPAR.

CONAE - Conferência Nacional de Educação. (2010). Construindo o Sistema Nacional Articulado de Educação: o Plano Nacional de Educação, diretrizes e estratégias. Documento Final. Brasília. Recuperado de: <http://conae.mec.gov.br/images/stories/pdf/pdf/documetos/documento_final.pdf>. Acesso em: 24 ago. 2014.

Cruz, S. M. S. C. S. (2001). Aprendizagem centrada em eventos: uma experiência com enfoque ciência, tecnologia e sociedade no ensino fundamental. Florianópolis: UFSC.

Cysneiros, P. G. (2000). Novas tecnologias no cotidiano da escola. Anais... In: 23a ANPEd, Caxambu. 
Dourado, L. F. (2007). Políticas e gestão da educação básica no Brasil: limites e perspectivas. Educação Social, 28 (100), 921-946.

Drucker, P. (2000). A nova sociedade das organizações. In: HOWARD, R. (Org.) Aprendizado organizacional. Rio de Janeiro: Campus.

FNDE - Fundo Nacional de Desenvolvimento da Educação. Apresentação (2014). Recuperado de: <http://www.fnde.gov.br/financiamento/fundeb/fundeb-apresentacao>. Acesso em 21 de jun. 2014.

Gil, A. C. (2002). Como elaborar projetos de pesquisa. 4a Ed. São Paulo: Atlas.

Gouveia, A. B., \& Pelona, A. (2010). Recursos do FNDE e sua importância nos municípios da Região Metropolitana de Curitiba. Revista Eletrônica Política e Gestão Educacional, 9, 1-14.

Gouveia, A. B., \& Souza, A. R. (2010). Perspectivas e desafios no debate sobre financiamento e gestão da educação: da CONAE a um novo PNE. Educação Social, 31 (112), 789-807.

Imbernón, F. (2000). A educação no século XXI. Porto Alegre: ARTMED.

INESC - Instituto de Estudos Socioeconômico. Criança e adolescente no parlamento. (2012). Recuperado de: <http://www.inesc.org.br/biblioteca/textos/boletins/crianca-e-adolescente-noparlamento>. Acesso em: 20 jun. 2014.

ITS - Instituto de Tecnologia Social. (2004). Caderno de Debates - Tecnologia social no Brasil. São Paulo.

Jacobi, P., \& Pinho, J.A. (2006). Inovação no campo da gestão pública: novos desafios, novos patamares. Rio de Janeiro: FGV.

Jenkins, H. (2008). Cultura da convergência. São Paulo: Aleph.

Kramer, S., \& Nunes, M. F. (2007). Gestão pública, formação e identidade de profissionais de educação infantil. Cadernos de Pesquisa, 37 (131), 423-454.

Koepsel, R. (2003). CTS no Ensino Médio: aproximando a escola da sociedade. Dissertação (Mestrado em Educação). Universidade Federal de Santa Catarina, Florianópolis.

Leal, M. C. E, \& Gouvêa, G. (2001). Uma visão comparada do ensino em ciência, tecnologia e sociedade na escola e em um museu de ciência. Ciência \& Educação, 7 (1), 67-84.

Medina, M., \& Sanmartín, J. (1990). El programa tecnología, ciencia, natureza y sociedad. In: MEDINA, M. (Org.). Ciencia, tecnología y sociedad: estudos interdisciplinares em La universidad, em La educación y em la gestión pública. Barcelona: Anthropos.

Mitrulis, E. (2002). Ensaios de inovação no ensino médio. Cadernos de Pesquisa, 116, 217-244.

Mortimer, E. F., \& Santos, W. L. P. (2000). Uma análise de pressupostos teóricos da abordagem CT-S (Ciência-Tecnologia-Sociedade) no contexto da educação brasileira. Ensaio - Pesquisa em Educação em Ciências, 2 (2), 133-162.

Oliveira, C. B. E. (2005). Ensino fundamental: papel do professor, motivação e estimulação no contexto escolar. Brasília.

Oliveira, D.A. (2000). Educação básica: gestão do trabalho e da pobreza. Petrópolis: Vozes. 
Peroni, V. M. V., Oliveira, R. T. C., \& Fernandes, M. D. E. (2009). Estado e terceiro setor: as novas regulações entre o público e o privado na gestão da educação básica brasileira. Educação Social, 30 (108), 761-778.

Pinheiro, N.A.M. (2004). Uma experiência matemática sob o enfoque CTS: subsídios para discussões. Revista Perspectiva, 28, p. 33-49.

Pinheiro, N.A.M. (2005). Educação crítico-reflexiva para um ensino médio científico tecnológico: a contribuição do enfoque CTS para o ensino aprendizagem do conhecimento matemático. Tese (Doutorado em Educação Científica e Tecnológica). Universidade Federal de Santa Cartarina, Florianópolis.

Pinheiro, N.A.M.; Silveira, R. M. C. F., \& Bazzo, W. A. (2007). Ciência, tecnologia e sociedade: a relevância do enfoque CTS para o contexto do ensino médio. Ciência \& Educação, 13 (1), 71-84.

Pinheiro, T. (2009). Tecnologia na aula. Revista Nova Escola, ed. 228. Disponível em: <http://revistaescola.abril.com.br/formacao/tecnologia-aula-computador-escola-pesquisafundacao-victor-civita-aprendizagem-518769.shtml>. Acesso em: 21 jun. 2014.

Pino, I. R. (2008). As TIC na formação à distância: reflexões contemporâneas. Retratos da Escola, 2 (2-3), 109-120.

PNUD - Programa das Nações Unidas para o Desenvolvimento. (2010). Ranking IDH municípios 2010. Disponível em: <http://www.pnud.org.br/atlas/ranking/Ranking-IDHM-Municipios2010.aspx>. Acesso em: 18 set. 2014.

Portal Aprender São Caetano. Aprimora ensino fundamental. São Caetano do Sul: PMSCS. (2014). Disponível em: <http://www.aprendebrasil.com.br/sites/secretarias/ aprendersaocaetano.com.br/site/ >. Acesso em: 12 set. 2014.

Prensky, M. (2010). O papel da tecnologia no ensino e na sala de aula. Conjectura, 15 (2).

Rodrigues, I., \& Barbieri, J. C. (2008). A emergência da tecnologia social: revisitando o movimento da tecnologia apropriada como estratégia de desenvolvimento sustentável. RAP - Revista de Administração Pública, 42 (6), 1069-1094.

Rodrigues, G. S. S. C, \& Colesanti, M. T. de M. (2008). Educação ambiental e as novas tecnologias de informação e comunicação. Sociedade \& Natureza, 20 (1), 51-66.

Santos, G. M. C., \& Barros, D. M. V. (2008). Escola de tempo integral: a informática como princípio educativo. Revista Iberoamericana de Educación, 46 (8), 1-11.

Sanz, M. A., Mortalla, T. D., \& Gómez, Y. H. (1996). Ciencia, tecnología y sociedad. Madrid: Noesis.

Schumpeter, J. A. (1984). Capitalismo, socialismo e democracia. Rio de Janeiro: Zahar.

Selwyn, N. (2008). O uso das TIC na educação e a promoção de inclusão social: uma perspectiva crítica do Reino Unido. Educação Social, 29 (104), 815-850.

Senge, P. (1996). Conduzindo organizações voltadas para o aprendizado: o destemido, o poderoso e o invisível. In: Hesselbein, F., Goldsmith, M., \& Beckhard, R. (Orgs.). O líder do futuro. São Paulo: Futur.

Tidd, J., Bessant, J., \& Pavitt, K. (2004). Managing innovation: integrating technological, market and organizational change. Chichester: John Wiley\&Sons Ltd. 
Tortajada, J. F. T., \& Peláez, A. L. (1997). Ciencia, tecnología y sociedad. Madrid: Sistema.

Zuin, A. A. S. (2010). O plano nacional de educação e as tecnologias da informação e comunicação. Educação Social, 31 (112), 961-980. 